\title{
Benign anorectal disease: hemorrhoids, fissures, and fistulas
}

\author{
Ivy H. Gardner, Ragavan V. Siddharthan, Vassiliki Liana Tsikitis \\ Oregon Health and Science University, OR, USA
}

\begin{abstract}
Hemorrhoids, anal fissures, and fistulas are common benign anorectal diseases that have a significant impact on patients' lives. They are primarily encountered by primary care providers, including internists, gastroenterologists, pediatricians, gynecologists, and emergency care providers. Most complex anorectal disease cases are referred to colorectal surgeons. Knowledge of these disease processes is essential for proper treatment and follow up. Hemorrhoids and fissures frequently benefit from non-operative treatment; they may, however, require surgical procedures. The treatment of anorectal abscess and fistulas is mainly surgical. The aim of this review is to examine the etiology, diagnosis, medical, and surgical treatment for these benign anorectal diseases.
\end{abstract}

Keywords Hemorrhoids, fissures, fistula, abscess, benign anorectal disease

Ann Gastroenterol 2020; 33 (1): 1-10

\section{Introduction}

Benign anorectal disease is commonly encountered in clinical practices across specialties and hemorrhoids, fissures, and fistulas continue to have a significant impact on patients' lives. Hemorrhoids and fissures frequently benefit from nonoperative management, but occasionally require surgery, while the treatment of anorectal abscess and fistulas is mainly surgical. The aim of this review is to examine the etiology, diagnosis, medical, and surgical treatment for these benign anorectal diseases.

\section{Hemorrhoids}

The prevalence of self-reported hemorrhoids in the US is $4-8 \%$; about one third of these present for treatment $[1,2]$. Epidemiological data from the UK demonstrates a hemorrhoid prevalence of $13-36 \%$ within the general population, probably an overestimate [3]. Based on screening colonoscopy data, about $38 \%$ of the population has hemorrhoids, and only $44 \%$ of those with hemorrhoids on colonoscopy reported

Department of General Surgery, Division of Gastrointestinal and General Surgery Portland, Oregon Health and Science University, OR, USA

Conflict of Interest: None

Correspondence to: Vassiliki Liana Tsikitis, MD, MBA, MCR, FACS, FASCRS, 3181 SW Sam Jackson Park Road Mailcode L223A Portland, Oregon 97239, USA, e-mail: tsikitis@ohsu.edu

Received 18 July 2020; accepted 4 October 2020; published online 29 November 2019

DOI: https://doi.org/10.20524/aog.2019.0438 symptoms [4]. Middle age (45-65 years old) and obesity are the primary risk factors $[2,4]$.

Hemorrhoidal columns are normal anatomic clusters of vascular and connective tissue, smooth muscle, and overlying epithelium that exist in the left lateral, right anterior, and right posterior anal canal and serve in providing continence. They become pathologic when engorged and subsequently symptomatic. Internal hemorrhoids are proximal to the dentate line, covered in columnar epithelium, and have visceral innervation. Internal hemorrhoids are clinically classified when they become symptomatic: Grade 1 hemorrhoids do not prolapse; Grade 2 prolapse with straining; Grade 3 require manual reduction to reduce prolapse; and Grade 4 are irreducible. External hemorrhoids are perianal subcutaneous venous plexuses distal to the dentate line, somatically innervated, and covered by squamous epithelium. External hemorrhoids may become pathological when these venous plexuses spontaneously rupture, resulting in a painful subcutaneous hematoma or "thrombosed external hemorrhoid."

The etiology of hemorrhoids was originally thought to be caused by portal hypertension; however, the most popular modern theory is that symptomatic hemorrhoids occur with deterioration of the tissues that support the anal cushions, causing abnormal downward displacement and venous dilation [5-7]. This process can be exacerbated by lifting, straining, and prolonged sitting. Other risk factors include a low fiber diet and constipation, though epidemiological studies have shown that hemorrhoids and constipation have different distributions among the population $[2,8]$. Some studies have shown that diarrhea, rather than constipation, is associated with hemorrhoids $[9,10]$. Given the high prevalence of hemorrhoids in developed countries versus developing countries, some have postulated that posture during defecation may play a role in 
causing symptomatic hemorrhoids. Studies have shown that squatting produces a straighter anorectal angle, compared to sitting on a toilet $[11,12]$.

\section{Diagnosis}

Internal hemorrhoids most often present with painless bleeding during bowel movements and/or prolapse. Prolapse may be associated with mild fecal incontinence, mucous drainage, perianal fullness, and painful skin irritation. Although rare, prolapsed internal hemorrhoids can strangulate, causing significant pain. Thrombosed external hemorrhoids tend to be more painful, given their somatic innervation, and patients present with a tender perianal mass that can bleed if it ulcerates. Thrombosed external hemorrhoids usually degenerate into perianal skin tags over time. The diagnosis of hemorrhoidal disease is based on history and physical exam. It is important to not blindly attribute painless rectal bleeding to hemorrhoids without a proper physical exam and further workup. Anoscopy is necessary to visualize internal hemorrhoids and identify anorectal pathology on exam. In the US, common practice is that painless rectal bleeding with a normal anoscopic evaluation is followed by diagnostic colonoscopy [13].

\section{Medical treatment}

Symptomatic hemorrhoids tend to be self-limiting and often respond well to conservative medical treatment: increasing fluid and fiber intake, regular exercise, avoiding constipation and straining, and spending less time on the toilet. A meta-analysis of 7 randomized trials comparing fiber supplementation (7-20 g/day) to no fiber showed that fiber supplementation decreases bleeding symptoms by $50 \%$, but had little effect on prolapse, pain, and itching from hemorrhoids [14]. There is no evidence to support the use of popular topical over-the-counter remedies like Preparation H or topical corticosteroids $[15,16]$.

\section{Rubber band ligation}

Rubber band ligation is the most commonly performed office procedure for bleeding grade II and III hemorrhoids. During this procedure, a rubber band is placed around a hemorrhoidal column, causing tissue necrosis and fixation to the mucosa. Necrosis usually occurs in 3-5 days, followed by ulceration and healing in several weeks. Rubber band ligation cannot be performed on external hemorrhoids because of their somatic innervation. Other contraindications include patients on anticoagulation or with a coagulopathy, as there is a risk of significant bleeding. The procedure is done in office, with the patient in a jackknife prone position and without anesthesia. An anoscope is used to visualize the hemorrhoids, and rubber bands are deployed at least half a centimeter above the dentate line. It is important to confirm that there is no pain before and after placement. Common complications include pain, urinary retention, delayed bleeding, and perineal sepsis. A retrospective review of 805 patients and 2114 rubber band ligations found an overall success rate of $80 \%$, with complications such as bleeding $(2.8 \%)$, thrombosis of external hemorrhoid $(1.5 \%)$ and bacteremia (0.09\%) [17].

\section{Sclerotherapy}

Sclerotherapy is another office-based procedure for treating internal grade I and II hemorrhoids. This is an especially good treatment for those on anticoagulation or with coagulopathy. Similarly to rubber band ligation, the procedure is performed with an anoscope and without anesthesia to visualize the hemorrhoids and inject them with a sclerosant, such as 5\% phenol in vegetable oil, ethanolamine, quinine or hypertonic saline [15]. This causes fibrosis and fixation of the tissue to the anal canal, effectively obliterating the redundant hemorrhoidal tissue.

Infrared coagulation is a variation of sclerotherapy where hemorrhoids are sclerosed using an infrared coagulator. The procedure is performed similarly, but instead of sclerosant, an infrared coagulator is applied to the base of the hemorrhoids for $2 \mathrm{sec}$, 3-5 times, until white blanched mucosa is seen, eventually causing scaring and retraction of the prolapsed mucosa.

A meta-analysis of 18 trials comparing rubber band ligation and sclerotherapy showed that rubber band ligation had a better cure rates for grade I-III hemorrhoids, with no difference in complication rates [18]. Rubber band ligation tended to cause more pain initially, but was less likely to be followed by recurrence of symptoms [18]. Infrared coagulation and sclerotherapy were more likely to require additional procedures compared to rubber band ligation [18].

\section{Surgical treatment}

Surgical treatment is indicated for grade III or IV internal hemorrhoids and for thrombosed external hemorrhoids with persistent symptoms. Excision is recommended within the first $48 \mathrm{~h}$ of symptoms for thrombosed external hemorrhoids. Incision and drainage is ineffective, and complete excision of the hemorrhoid with the associated external skin is advised. This procedure can take place in the clinic or in an emergency care setting with local anesthesia. A retrospective review of 231 patients comparing excision to non-operative treatment of thrombosed external hemorrhoids showed that excision symptoms resolved on average in 3.9 days (vs. 24 days in the non-operative group) and were less likely to recur [19].

Acute hemorrhoid crisis is rare, and will appear as beefy red, ulcerated or necrotic hemorrhoids on examination. This occurs when internal hemorrhoids prolapse and become incarcerated as a result of sphincter spasm and warrants hospital admission. It is not uncommon to have concurrent thrombosed external hemorrhoids. Most patients with acute hemorrhoid crisis benefit from hospitalization and conservative management, 
including bowel rest, pain control and sitz baths [20]. Necrotic hemorrhoids and/or perineal sepsis are indications for urgent exploration and excision.

\section{Hemorrhoidectomy}

There are 2 approaches to hemorrhoidectomy: the Ferguson (closed) and the Milligan-Morgan (open) technique. Both use elliptical incisions starting at the perianal skin; the Ferguson technique closes the wound primarily while the MilliganMorgan technique leaves the wounds open (Fig. 1). The critical step of the procedure is to ensure that the hemorrhoidal tissue is dissected off the sphincter before the vascular pedicle is ligated. One to three columns may be excised. The Milligan-Morgan technique tends to be more popular in the UK and is preferred for gangrenous hemorrhoids. There is no difference in the resolution of symptoms between the 2 approaches, but the Ferguson technique induces faster wound healing [21]. The most concerning long-term complication is incontinence due to sphincter injury. One study reported sphincter muscle fibers in up to $15 \%$ of hemorrhoidectomy specimens [22]. Given the role normal hemorrhoidal cushions play in continence, hemorrhoidectomy can cause changes in continence postoperatively, even without direct injury to the sphincter [23]. Anal stenosis is a late complication of hemorrhoidectomy, and is related to the amount of tissue excised [23].

\section{Stapled hemorrhoidopexy}

Stapled hemorrhoidopexy is another surgical method for grade II and III hemorrhoids that uses a stapler device to resect and, more importantly, fixate tissue to the rectal wall. The critical step of the procedure is making a circumferential purse string suture in the submucosa about $4 \mathrm{~cm}$ from the dentate line that does not include any sphincter muscle. If the purse string is low in the rectum, it will cause pain; if too

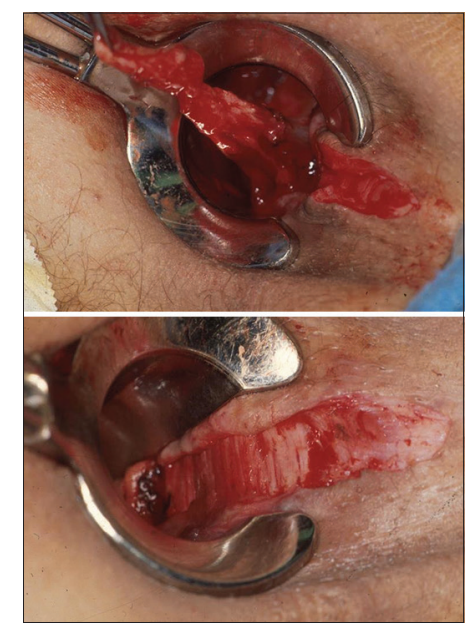

Figure 1 Open hemorrhoidectomy. An elliptical incision is made starting at the perianal skin and extending proximally to incorporate the entire hemorrhoidal column. The hemorrhoidal tissue is dissected off the sphincter, visible in the bottom picture deep, the stapler may make a full-thickness excision through the rectal wall. This could be followed by abscess or fistula, possibly requiring surgical revision [20]. It is imperative for the surgeon to be familiar with the specific stapler kit used and to ensure the vagina is not within bite of the stapler before it is fired. Complications include bleeding, sphincter muscle injury, anastomotic line dehiscence, stenosis, and recto-vaginal fistula. One randomized controlled trial, comparing open hemorrhoidectomy to stapled hemorrhoidopexy showed that stapled hemorrhoidopexy patients had less postoperative pain during bowel movements, earlier bowel movements post-op, shorter hospital stays, and fewer narcotic requirements [24]. This study showed no differences in post-op complications, but the stapled group had more frequent recurrence of prolapse at 2 years [24]. Multiple meta-analyses have confirmed that stapled hemorrhoidopexy has higher rates of recurrence than hemorrhoidectomy [25-27]. A 2010 multicenter randomized trial in Europe showed equal rates of recurrence, but more symptomatic relief with formal hemorrhoidectomy [28]. Overall, the use of stapled hemorrhoidopexy has declined significantly in Europe over the past decade.

\section{Doppler-guided hemorrhoidal artery ligation}

Doppler-guided hemorrhoidal artery ligation, also called transanal hemorrhoidal dearterialization, is a non-excisional surgical method to produce hemorrhoidal shrinkage that uses a Doppler probe to identify the 6 main feeding arteries in the anal canal and ligates the ones feeding the symptomatic hemorrhoids. The redundant tissue may also be plicated to perform a mucopexy during the procedure. Initial studies showed promising results for this method, but randomized trials have now demonstrated more mixed results. Two randomized trials comparing Doppler-guided hemorrhoidal artery ligation to open hemorrhoidectomy showed less postoperative pain in the hemorrhoidal artery ligation group and no significant difference in recurrence at one year $[29,30]$. In contrast, a third randomized trial showed no difference in postoperative pain, complications or recurrence between the hemorrhoidal artery ligation and open hemorrhoidectomy groups [31].

It remains unclear what the best treatment for hemorrhoids is, as there is significant heterogeneity in the methodologies applied and the study endpoints examined in all the aforementioned studies [15]. Additionally, surgeon bias affects the techniques used, and indications depend on the operator and their experience [15]. Another confounding factor in these studies is that patients and providers often define recurrence differently after treatment, but the European Society of Coloproctology has recently developed a Core Outcome Set to address this shortcoming of the current literature [32]. A meta-analysis of 98 randomized clinical trials concluded that, although hemorrhoidectomy is associated with higher reported postoperative pain than hemorrhoidal artery ligation and stapled hemorrhoidopexy, it yields the lowest recurrence rates. Overall, the authors concluded formal hemorrhoidectomy should be considered the standard for surgical care of hemorrhoidal disease, but surgical treatment 
should be tailored to each patient's symptoms and exam findings [33].

\section{Fissures}

An anal fissure is a linear tear in the anal mucosa, usually extending from the dentate line to the anal verge. Anal fissures are common, but no population studies have elucidated their exact incidence. Fissures occur in all age groups, but appear to be more common in young and otherwise healthy people. If one persists for more than 4-8 weeks, it is considered chronic. Most fissures occur at the posterior midline (90\%) [34-36]. Anterior midline fissures occur in $10-25 \%$ of female fissures and $1-8 \%$ of male fissures [34-36]. Anterior and posterior midline fissures can occur concomitantly in about $3 \%$ of cases [34]. A lateral fissure should raise concern for inflammatory bowel disease, tuberculosis, human immunodeficiency virus, or syphilis. Anal fissures cause significant pain and negatively impact quality of life [37].

Anal fissures were initially thought to be due to anal canal trauma from hard stools or diarrhea, but this explains only acute fissures. Additionally, constipation and hard bowel movements are only reported in $13 \%$ of patients with fissures [36]. It appears that persistently high internal sphincter tone leads to chronicity of fissures [38]. Pain from the fissure itself contributes to the increased sphincter tone, but persists even after local anesthetic is applied [38]. These changes in tone appear to be pathological, and can persist for long periods of time. One study showed that internal sphincter biopsies taken at the time of internal sphincterotomy for chronic anal fissure have less nitric oxide present compared to internal sphincters from abdominoperineal resection specimens [39]. The increased internal sphincter tone causes local ischemia that prevents the fissure from healing, creating a chronic wound. The anoderm is supplied by the inferior rectal arteries after it traverses the internal sphincter. Studies illustrate that the perfusion of the anoderm is inversely related to the pressure of the internal sphincter [40]. Angiography and cadaver studies show that there is a paucity of arterioles in the posterior midline anal canal that explains the propensity for fissures to occur at this location $[41,42]$.

There is a separate entity of fissures associated with childbirth that appear to be due to shear forces from the baby's head during birth, causing tethering of the mucosa to muscle and local trauma [35]. About $11 \%$ of chronic fissures, associated with difficult or instrumented deliveries, occur after childbirth, and are most common in the anterior midline [35]. These fissures are not associated with increased sphincter tone, but have normal or even low tone, so sphincterotomy is not indicated for treatment [43].

\section{Diagnosis}

The diagnosis of anal fissure is a clinical one. Patients usually present with anal pain, most commonly for several hours after bowel movements, and may have painful bleeding with bowel movements. A fissure may be found upon examination, although this may be difficult because of pain and internal sphincter spasm. Chronic fissures develop indurated edges and may have visible sphincter muscle at the base with associated hypertrophic papilla proximally and sentinel tags distally (Fig. 2).

\section{Medical treatment}

Treatment of anal fissures starts with conservative treatment including stool softeners, fiber supplementation, sitz baths, and topical lidocaine gel for pain control. Stool softeners and lidocaine gel together will heal $8-51 \%$ of fissures, with most studies showing healing rates of $16-31 \%$ in acute and chronic fissures [35]. Almost half of acute fissures will heal with sitz baths and fiber, with or without lidocaine gel. The effect of topical steroids or lidocaine gel in healing fissures is equal to or worse than sitz baths and fiber [34]. Lidocaine by itself does not appear to contribute to healing of fissures, but provides symptom relief [44].

The goal of medical treatment of anal fissures is to decrease the internal sphincter tone and allow healing. Topical nitrate use leads to healing of chronic anal fissures in about $50 \%$ of patients, and demonstrates a $13.5 \%$ improvement in healing over placebo [34]. Up to $50 \%$ of fissures healed with nitrates have recurrences [34]. The topical nitrates commonly used are isosorbide dinitrate and glyceryl trinitrate. Since the advent of topical calcium channel blockers, nitrates are not usually used in the treatment of anal fissures, because of the common sideeffect of headaches that occur in a dose-related manner [34,45]. A double-blind multicenter randomized trial comparing nifedipine gel to topical hydrocortisone and lidocaine found that the nifedipine treatment healed fissures within 21 days in $95 \%$ of patients, compared to $50 \%$ in the control treatment group [46]. Additionally, anal manometry confirmed that nifedipine decreased the resting anal pressure by $30 \%$, whereas there was no change in the control group [46].

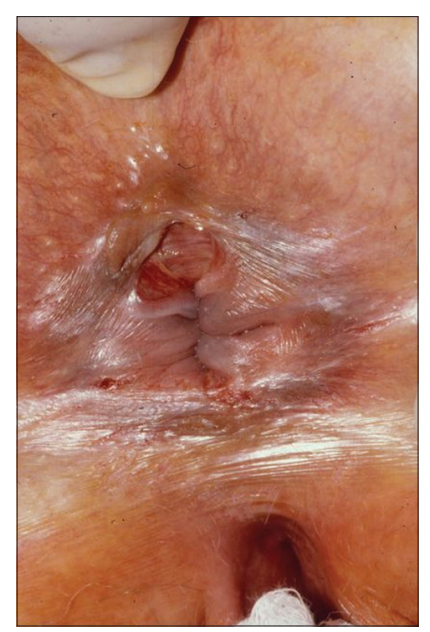

Figure 2 Chronic anal fissure with visible sphincter muscle at base of wound 
When the conservative management with topical ointment fails, another medical option is injection into the internal sphincter of botulinum toxin (Botox), which has healing rates ranging from $27-96 \%$ [35]. The most common side-effect is temporary incontinence, particularly to flatus, which can occur in up to $18 \%$ of patients [35]. A meta-analysis showed that Botox injection had no significant advantage over glyceryl trinitrate or placebo [44]. Overall, Botox injections have similar healing rates to those of other topical agents when used as a first-line agent, but better healing rates when compared to second-line agents [34,47]. One advantage of Botox over topical nitrates and calcium channel blockers is that it does not require the patient to adhere to a frequent application schedule or cause unpleasant headaches $[48,49]$. There does not appear to be an evidence-based ideal dose, preparation or injection site [34]. A meta-analysis comparing Botox to sphincterotomy showed that Botox had lower healing rates and lower rates of incontinence than sphincterotomy [50].

A Cochrane review of medical therapy for anal fissures, comprising 77 studies with a total of 5031 participants, showed that glyceryl trinitrate is marginally significantly better than placebo (48\% healed vs. 35\%) [51]. Botox and calcium channel blockers were shown to be equivalent to glyceryl trinitrate in efficacy, but with fewer side-effects [51]. Though no medical therapy comes close to the efficacy of sphincterotomy, such treatments do not carry a risk of permanent incontinence [44,51].

\section{Lateral internal sphincterotomy (LIS)}

LIS is the surgical treatment of choice for chronic fissures [34]. Multiple randomized studies show the superiority of LIS to nitrates, calcium channel blockers and Botox [34]. LIS has healing rates of $88-100 \%$, but is associated with incontinence rates of $8-30 \%$ [34]. Most of this incontinence is transient, and does not extend beyond 2 months; the incontinence rate beyond 2 months is 3-7\% [35]. Most recent studies show lower incontinence rates than were initially reported in the literature, with no study having rates greater than 3\% [52]. Recurrence rates of fissure after LIS is $0-15 \%$ [35]. LIS may be considered as the first-line surgical treatment in patients without prior obstetrical injury, inflammatory bowel disease, prior anorectal operations or sphincter injury [34]. Traditional LIS dictated that the sphincterotomy should be carried up to the dentate line. Tailored sphincterotomy extends just proximal to the fissure and has been shown to preserve sphincter, while it may improve incontinence rates [53]. The more sphincter cut, the higher the risk of incontinence and the lower the rate of recurrence [54]. There is no difference in outcomes between open or closed LIS [34,52]. LIS can be used on recurrent fissures if the sphincterotomy is done on the contralateral side [34].

\section{Local advancement flaps}

Local advancement flaps are the first line surgical treatment for chronic anal fissures associated with normal or low anal pressures. One study showed that subcutaneous advancement flap anoplasty led to healing of $94 \%$ of fissures without any incontinence; the $6 \%$ that recurred did so at a different location from the initial fissure [55]. Overall, local advancement flaps are a safe approach to treat chronic anal fissure wounds, with healing rates of $88-100 \%$ and a low risk of incontinence (0-6\%), but additional larger comparative trials are required to better delineate its role in the treatment of anal fissures [34]. Flap failure rates are a significant complication and occur in 5-11\% of patients. Patients can also develop mucosal discharge and perianal skin irritation if an ectropion is formed during flap advancement. A flap can be combined with sphincterotomy or Botox to address both the chronic wound and the underlying issue at the same time [34].

\section{Fissurotomy and fissurectomy}

Many fissures have subcutaneous tracts that extend distally from the chronic fissure to a sentinel tag. Fissurotomy is the act of incising that tract to release the perianal skin, therefore creating a widening of the anal canal. The wound is left open to heal by secondary intention. One prospective trial of 109 patients undergoing fissurotomy had resolution of symptoms in $98 \%$, with the other $2 \%$ requiring sphincterotomy [56].

Fissurectomy is the excision of the chronic fissure wound, curetting, and excision of a sentinel pile, if present. Fissurectomy is associated with a $3 \%$ recurrence rate and a $6 \%$ rate of incontinence [57]. Fissurectomy, in addition to isosorbide dinitrate cream for chemical sphincterotomy, resulted in all wounds healing within 10 weeks without recurrence, and no evidence of internal sphincter injury in one study [58]. Another study of fissurectomy plus Botox showed healed wounds at 16 weeks in $93 \%$ of fissures, and improvement in symptoms in all patients [59]. A Cochrane review of 27 studies comparing the surgical treatment of fissures, including a total of 2056 patients, found that sphincterotomy was less likely to result in treatment failure compared to fissurectomy, with a similar risk of incontinence [52]. LIS is still the standard surgical treatment for chronic anal fissures with increased sphincter tone in which medical management has failed.

\section{Perianal abscess and fistulas}

Anorectal abscesses represent a very common disease process that typically results from a cryptoglandular infection in the anal canal and can occur in the ischiorectal, intersphincteric, supralevator, perianal or submucosal spaces. They are more common in men and their incidence peaks around age 20-40 years [60]. Abscesses and fistula often occur concomitantly, with $30-70 \%$ of those with active abscesses having a current fistula [60]. Of people with anorectal abscesses who do not currently have a fistula, $30-50 \%$ will develop one in the future $[60,61]$.

An anal fistula is a persistent epithelialized tract from the anal canal to the perianal skin, and can be intersphincteric, 
transsphincteric, suprasphincteric, or extrasphincteric. Fistulas are considered simple if they are low transsphincteric or intersphincteric and cross less than $30 \%$ of the external sphincter [60]. Complex fistulas include those that are high transsphincteric (involving more than $30 \%$ of the external sphincter), extrasphincteric or suprasphincteric, and cryptoglandular in origin, in addition to fistulas associated with inflammatory bowel disease, radiation, malignancy, chronic diarrhea or preexisting incontinence [60]. Eighty percent of fistulas are secondary to cryptoglandular infection, with the remainder due to Crohn's disease, trauma, radiation, malignancy or various infectious diseases [60].

The mainstay management of fistulas is surgical, though there is an extensive variety of procedures, including fistulotomy with or without prior seton placement, fibrin glue or plug, endorectal advancement flap, and ligation of intersphincteric fistula tract (LIFT). Regardless of the procedure, the most critical step is finding the internal opening of the fistula. Goodsall's rule attempts to predict the site of the internal opening relative to the external opening. It dictates that if the external opening is anterior to an imaginary transverse line drawn through the anal verge, then the internal opening will be located radially relative to the external opening and the fistula tract will be linear. If the external opening is located posterior to the imaginary transverse line (often in the posterior midline), then the fistula tract may follow a curved or complicated trajectory. Studies have shown that Goodsall's rule predicts the location of the internal opening in $49-91 \%$ of fistulas, with a positive predictive value of 59\% [62]. The rule appears more accurate for posterior fistulas (90\% accurate), compared to anterior fistulas (57\% accurate in men and $31 \%$ in women) [63]. If an anterior fistula does not tract radially, then it is most likely to tract to the midline [63]. The external opening of a fistula does not predict the internal opening in patients with long fistulas, Crohn's disease or recurrent fistulas.

\section{Diagnosis}

The diagnosis of anorectal abscess or fistula is generally based on history and exam [61]. Patients with a perianal or ischiorectal abscess will present with fever, pain, tenderness, erythema and often a fluctuant mass. Patients with supralevator or intersphincteric abscesses may have minimal external exam findings, but will have rectal tenderness and fluctuance on digital rectal exam [61]. It is vital to differentiate an anorectal abscess from other inflammatory processes that may occur in the area, such as hidradenitis, furuncles, or pilonidal disease. Computed tomography with intravenous contrast can be useful to localize high abscesses, especially supralevator abscesses.

Fistulas will present with persistent purulent or fecal drainage or intermittent perianal swelling and tenderness relieved with spontaneous drainage. Multiple fistulas and large skin tags can be suggestive of Crohn's disease [61]. Imaging is not required for workup of routine fistulas, since the tract can often be delineated with an exam under anesthesia. If the fistula proves difficult to characterize, rectal magnetic resonance imaging may prove useful, with accuracy rates $>90 \%$ for fistula mapping [61]. Endorectal ultrasound can also be used to map out fistulas, with accuracy rates of $80-89 \%$ [61].

\section{Incision and drainage}

Anorectal abscesses require incision and drainage for treatment. Since many of them will develop into fistula, it is important to keep the incision as close as possible to the anal verge to minimize the length of a potential fistula. The rate of recurrence after drainage requiring repeat drainage is $3-44 \%$ [61]. Antibiotics are recommended in addition to drainage for patients who are immunocompromised, septic, or have significant cellulitis. If a fistula is present, initial drainage and fistulotomy of a concomitant fistula has an $83 \%$ lower incidence of abscess recurrence compared to drainage alone, though this is associated with an increased risk of fecal incontinence [64]. It is recommended that initial fistulotomy is reasonable to perform during incision and drainage if the fistula is simple and the benefits appear to outweigh the risks for the patient [60].

\section{Fistulotomy}

The overall goal of fistula surgery is to obliterate the internal os and epithelialized tract with minimal sphincter division. The internal os can be found by injecting hydrogen peroxide or methylene blue through the external os with an anoscope in place. Simple fistulas can be treated by fistulotomy. Fistulotomy is performed by identifying the internal and external os, placing a probe through the tract, and incising the tissue overlying the probe (Fig. 3). This usually requires division of a portion of the external sphincter and there is controversy on how much can be divided without affecting continence. Success rates of fistulotomy are excellent in the majority of patients, at 92-97\% (Table 1) [61]. The literature reports a large range of changes in continence after fistulotomy, from $0-73 \%$ [61]. Risk factors for postoperative incontinence after fistulotomy are preoperative incontinence,

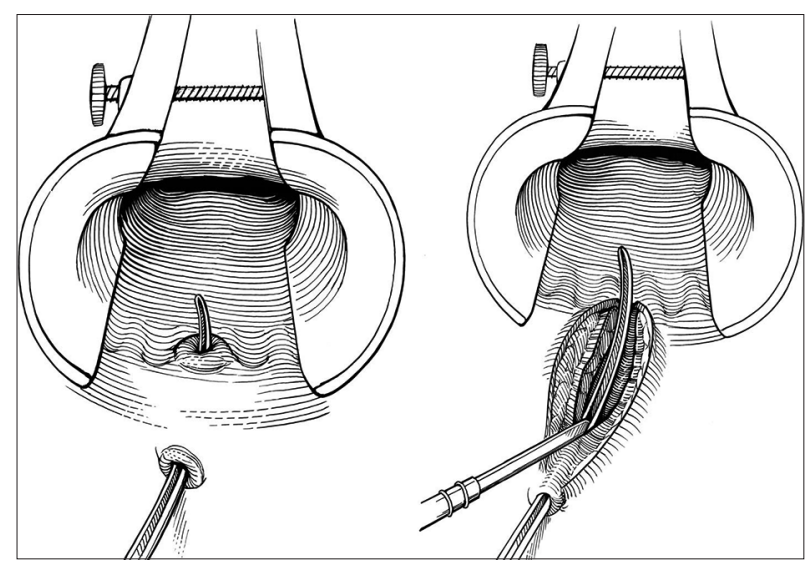

Figure 3 Fistulotomy. A probe is inserted through the external os to the internal os and the fistulous tract is opened over the probe 
Table 1 Procedures for treatment of fistulas

\begin{tabular}{lccc}
\hline Procedure & Success rate & Recurrence rate & Incontinence rate \\
\hline Fistulotomy & $92-97 \%[61]$ & $7 \%[65]$ & $0-73 \%[61]$ \\
Fibrin glue & $10-78 \%[60,67]$ & $6 \%[68]$ & $0 \%[69]$ \\
\hline Plug & $81 \%[71]$ & $71 \%[72]$ & $1 \%[73]$ \\
Advancement flap & $66-87 \%[60]$ & $13-56 \%[61]$ & $7-38 \%[61]$ \\
Cutting seton & $90 \%[60]$ & $0 \%[74]$ & $12-54 \%[73,74]$ \\
Seton + fistulotomy & $62-100 \%[61]$ & $0-32 \%[79]$ & $0-54 \%[61]$ \\
LIFT & $40-95 \%[61,79]$ & $* *$ & $0-63 \%[79]$ \\
Laser ablation & $33-64 \%[80,81]$ & $0-5.9 \%[81]$ \\
\hline
\end{tabular}

** Insufficient studies to determine

LIFT, ligation of intersphincteric fistula tract

female sex, complex fistulas, prior fistula surgery, and recurrent disease. One study indicated that patients with low fistulas treated by fistulotomy had soiling rates of $40 \%$ after surgery, with $7 \%$ recurrence at 3 years [65]. Recurrence after fistulotomy can be due to inadequate delineation of the fistula tract, failure to identify a secondary fistula tract, or the patient's predisposition for cryptoglandular disease [66]. Marsupialization of the tract during fistulotomy is associated with less postoperative bleeding and better wound healing [61]. Fistulectomy is excision of the entire fistula tract, and is associated with longer healing times, larger wounds, high rates of incontinence and similar recurrence rates, compared to fistulotomy [61]. Fistulectomy is rarely performed, as it yields similar results and worse side-effects compared with fistulotomy.

\section{Fibrin glue}

Debridement and injection of fibrin glue in the fistula tract is an antiquated treatment of fistulas. Retrospective and prospective cohort data has shown that use of fibrin glue has healing rates of $14-63 \%$ [60]. A meta-analysis of fibrin glue showed an overall healing rate of $53 \%$, with wide variation and an overall trend for studies with complex fistulas to report worse outcomes [67-69]. Overall, because of its low healing rates and high recurrence rates, fibrin glue injection has been outmoded.

\section{Fistula plug}

Plugging the internal fistula os with a bioprosthetic plug made of acellular collagen matrix is another treatment method. Early data showed promising success rates of 70-100\% for low fistulas, but long-term data for complex fistulas show success rates of less than $50 \%$ [61]. Plugs made of other biosynthetic matrices have shown similar patterns of early promising results, but ultimately have poor long-term success rates of less than $50 \%[60,70]$. One retrospective study showed healing rates of $81 \%$ after plug deployment, and found that smoking, posterior fistulas, and prior failed plug were predictive of plug failure [71].
A blinded multicenter randomized clinical trial comparing fistula plug to mucosal advancement flap found that recurrence rates were $71 \%$ with the plug and $52 \%$ with the flap, although these were not shown to be significantly different [72]. They also found no difference between the 2 groups in incontinence, postoperative pain, or quality of life [72].

\section{Endoanal advancement flaps}

Endoanal advancement flaps have been shown to have cure rates of $66-87 \%$ in the literature [60]. If the initial flap fails, another can be performed with similar success rates [60]. Patients may develop mild to moderate incontinence after endoanal advancement flaps $7-38 \%$ of the time [61]. Recurrence rates after endoanal advancement flap are 13-56\%, with no difference after adding fibrin glue to the tract [61]. Factors associated with failed flap repair are Crohn's disease, proctitis, rectovaginal fistula, malignancy, and prior repair attempts.

\section{Seton and staged fistulotomy}

A seton is a suture, rubber band or vessel loop passed through the fistula tract, where it allows drainage and converts an inflammatory process to a foreign body reaction, causing perisphincteric fibrosis. This often causes shortening of the tract and decreases the amount of sphincter involved, allowing for subsequent fistulotomy in cases where initially too much sphincter muscle was involved. Cutting setons work through progressive tightening of the seton, and create a gradual fistulotomy with scarring of the tract over time. Although their use has been reported to have healing rates of over $90 \%$, they can cause sphincter injury, and have therefore lost favor [60]. A meta-analysis of cutting setons showed incontinence rates of $12 \%$ with higher rates for higher fistulas $[73,74]$.

Overall, there is a relative lack of data regarding the use of setons [61]. Non-cutting setons are often placed to treat sepsis and cause fibrosis of the tract, followed by fistulotomy weeks later, resulting in success rates of $62-100 \%$ with incontinence rates of $0-54 \%$ (although this is mostly incontinence to flatus 
alone) [61]. One retrospective review of patients treated by seton (including daily rotation of the seton by one revolution in each direction by the patient) for high transsphincteric fistulas had gradual healing of the tract in $75 \%$ of patients [75]. Half of these patients had the tract migrate all the way to the surface, while the other half required fistulotomy [75].

\section{LIFT}

LIFT is a newer technique used to treat simple and complex transsphincteric fistulas. First described in 2007, it utilizes dissection in the intersphincteric plane to identify, suture ligate, and divide the intersphincteric fistula tract. It is often performed after a seton has been in place for 8 weeks or more to allow fibrosis of the tract. Success rates after LIFT are 57$94 \%$, with recurrence rates of $6-18 \%$ over a mean follow up of 3-8 months [61]. A retrospective review of LIFT with a follow up of 26 months found primary healing rates of $61 \%$, with $80 \%$ of failures occurring early postoperatively [76]. Longer tracts were associated with lower success rates [76]. A meta-analysis of the classic LIFT procedure found median healing rates of $79 \%$ and recurrence rates of $9 \%$ [77]. Those who did not heal with LIFT were often converted from a transsphincteric to an intersphincteric fistula then treated by fistulotomy [77]. Adding an endoanal advancement flap to the LIFT resulted in a primary healing rate of $51 \%$ and overall healing in $73 \%$ [77]. Adding a bioprosthetic plug to the external portion of the fistula tract in addition to performing LIFT resulted in healing in $95 \%$ of patients [77]. A randomized controlled trial comparing LIFT to endoanal advancement flap for complex fistulas after seton placement found that patients undergoing LIFT had shorter operative times, quicker return to work and similar rates of recurrence [78]. A meta-analysis of 26 studies showed success rates of $40-95 \%$, with low rates of postoperative changes in continence [79].

\section{Laser ablation}

The most recent and minimally invasive treatment for fistulas is the use of "Fistula Laser Closing" or FiLaC. This technique uses a radial emitting disposable laser fiber for endofistular ligation of the tract. This can also be supplemented with an endoanal advancement flap. A study of 117 patients at a single institution showed a $64 \%$ healing rate, with no fecal incontinence and a $1.7 \%$ rate of incontinence to flatus [80]. Another study of 30 patients had a much lower overall success rate of $33 \%$ and revealed that shorter fistulas $(<30 \mathrm{~mm})$ had a much higher success rate (58\%) compared to longer fistulas (17\%) [81]. Additional research is required before this technique is more widely adopted.

In conclusion, there are no randomized studies comparing all the different procedures used to treat fistulas. Given the variability in fistula anatomy, there is likely to be no single best method for treatment. Simple fistulas are best treated by fistulotomy, although this does come with a small risk of incontinence. Complex fistulas may be managed initially by seton placement to allow resolution of sepsis and fibrosis of the tract prior to definitive treatment. This sometimes converts a complex fistula into a simple one amenable to fistulotomy. Fibrin glue and plugs are generally low-risk procedures and may be used to treat complex fistula, but they have low overall success rates. LIFT and endoanal advancement flaps generally have higher success rates. Complex fistulas still remain challenging, even for the experienced colorectal surgeon. There are many surgical procedures that promise resolution; however, they carry either low healing rates or high recurrence rates. Furthermore, since multiple procedures that carry a risk of incontinence may be required for complete resolution, a specialist is recommended.

\section{Acknowledgments}

The authors would like to thank Dr. Santhat Nivatvong for the contribution of images from his personal library for this article.

The authors would like to thank Mary Kwatkosky-Lawlor and Priya Chinnaswamy-Veerappan for their assistance in the editing and submission of this article.

\section{References}

1. Nelson RL, Abcarian H, Davis FG, Persky V. Prevalence of benign anorectal disease in a randomly selected population. Dis Colon Rectum 1995;38:341-344.

2. Johanson JF, Sonnenberg A. The prevalence of hemorrhoids and chronic constipation. An epidemiologic study. Gastroenterology 1990;98:380-386.

3. Loder PB, Kamm MA, Nicholls RJ, Phillips RK. Haemorrhoids: pathology, pathophysiology and aetiology. BrJSurg 1994;81:946-954.

4. Riss S, Weiser FA, Schwameis $\mathrm{K}$, et al. The prevalence of hemorrhoids in adults. Int J Colorectal Dis 2012;27:215-220.

5. Goenka MK, Kochhar R, Nagi B, Mehta SK. Rectosigmoid varices and other mucosal changes in patients with portal hypertension. Am J Gastroenterol 1991;86:1185-1189.

6. Hosking SW, Smart HL, Johnson AG, Triger DR. Anorectal varices, haemorrhoids, and portal hypertension. Lancet 1989;1:349-352.

7. Thomson WH. The nature of haemorrhoids. BrJSurg 1975;62:542-552.

8. Burkitt DP, Graham-Stewart CW. Haemorrhoids-postulated pathogenesis and proposed prevention. Postgrad Med J 1975;51:631-636.

9. Johanson JF, Sonnenberg A. Constipation is not a risk factor for hemorrhoids: a case-control study of potential etiological agents. Am J Gastroenterol 1994;89:1981-1986.

10. Delcò F, Sonnenberg A. Associations between hemorrhoids and other diagnoses. Dis Colon Rectum 1998;41:1534-1541; discussion 1541-1542.

11. Tagart RE. The anal canal and rectum: their varying relationship and its effect on anal continence. Dis Colon Rectum 1966;9:449-452.

12. Sakakibara R, Tsunoyama K, Hosoi H, et al. Influence of body position on defecation in humans. Low Urin Tract Symptoms 2010;2:16-21.

13. Rex DK, Schoenfeld PS, Cohen J, et al. Quality indicators for colonoscopy. Gastrointest Endosc 2015;81:31-53. 
14. Alonso-Coello P, Mills E, Heels-Ansdell D, et al. Fiber for the treatment of hemorrhoids complications: a systematic review and meta-analysis. Am J Gastroenterol 2006;101:181-188.

15. Sandler RS, Peery AF. Rethinking what we know about hemorrhoids. Clin Gastroenterol Hepatol 2020;17:8-15.

16. Sun Z, Migaly J. Review of hemorrhoid disease: presentation and management. Clin Colon Rectal Surg 2016;29:22-29.

17. Iyer VS, Shrier I, Gordon PH. Long-term outcome of rubber band ligation for symptomatic primary and recurrent internal hemorrhoids. Dis Colon Rectum 2004;47:1364-1370.

18. MacRae HM, McLeod RS. Comparison of hemorrhoidal treatment modalities. A meta-analysis. Dis Colon Rectum 1995;38:687-694.

19. Greenspon J, Williams SB, Young HA, Orkin BA. Thrombosed external hemorrhoids: outcome after conservative or surgical management. Dis Colon Rectum 2004;47:1493-1498.

20. Rakinic J. Benign anorectal surgery: management. Adv Surg 2018;52:179-204.

21. Reis Neto JA, Quilici FA, Cordeiro F, Reis Júnior JA. Open versus semi-open hemorrhoidectomy: a random trial. Int Surg 1992;77:84-90.

22. Mirzaei R, Mahjoubi B, Kadivar M, Azizi R, Zahedi-Shoolami L. Anal sphincter injuries during hemorrhoidectomy: a multi center study. Acta Med Iran 2012;50:632-634.

23. Kunitake H, Poylin V. Complications following anorectal surgery. Clin Colon Rectal Surg 2016;29:14-21.

24. Gravié JF, Lehur PA, Huten N, et al. Stapled hemorrhoidopexy versus Milligan-Morgan hemorrhoidectomy: a prospective, randomized, multicenter trial with 2-year postoperative follow up. Ann Surg 2005;242:29-35.

25. Nisar PJ, Acheson AG, Neal KR, Scholefield JH. Stapled hemorrhoidopexy compared with conventional hemorrhoidectomy: systematic review of randomized, controlled trials. Dis Colon Rectum 2004;47:1837-1845.

26. Giordano P, Gravante G, Sorge R, Ovens L, Nastro P. Longterm outcomes of stapled hemorrhoidopexy vs conventional hemorrhoidectomy: a meta-analysis of randomized controlled trials. Arch Surg 2009;144:266-272.

27. Jayaraman S, Colquhoun PH, Malthaner RA. Stapled versus conventional surgery for hemorrhoids. Cochrane Database Syst Rev 2006;(4):CD005393.

28. Nyström PO, Qvist N, Raahave D, Lindsey I, Mortensen N; Stapled or Open Pile Procedure (STOPP) trial study group. Randomized clinical trial of symptom control after stapled anopexy or diathermy excision for haemorrhoid prolapse. Br J Surg 2010;97:167-176.

29. Elmér SE, Nygren JO, Lenander CE. A randomized trial of transanal hemorrhoidal dearterialization with anopexy compared with open hemorrhoidectomy in the treatment of hemorrhoids. Dis Colon Rectum 2013;56:484-490.

30. Denoya PI, Fakhoury M, Chang K, Fakhoury J, Bergamaschi R. Dearterialization with mucopexy versus haemorrhoidectomy for grade III or IV haemorrhoids: short-term results of a double-blind randomized controlled trial. Colorectal Dis 2013;15:1281-1288.

31. De Nardi P, Capretti G, Corsaro A, Staudacher C. A prospective, randomized trial comparing the short- and long-term results of doppler-guided transanal hemorrhoid dearterialization with mucopexy versus excision hemorrhoidectomy for grade III hemorrhoids. Dis Colon Rectum 2014;57:348-353.

32. van Tol RR, Kimman ML, Melenhorst J, et al. European Society of Coloproctology Core Outcome Set for haemorrhoidal disease: an international Delphi study among healthcare professionals. Colorectal Dis 2020;21:570-580.

33. Simillis C, Thoukididou SN, Slesser AA, Rasheed S, Tan E, Tekkis PP. Systematic review and network meta-analysis comparing clinical outcomes and effectiveness of surgical treatments for haemorrhoids. Br J Surg 2015;102:1603-1618.

34. Stewart DB Sr, Gaertner W, Glasgow S, Migaly J, Feingold D,
Steele SR. Clinical practice guideline for the management of anal fissures. Dis Colon Rectum 2017;60:7-14.

35. Poh A, Tan KY, Seow-Choen F. Innovations in chronic anal fissure treatment: A systematic review. World J Gastrointest Surg 2010;2:231-241.

36. Hananel N, Gordon PH. Re-examination of clinical manifestations and response to therapy of fissure-in-ano. Dis Colon Rectum 1997; 40:229-233.

37. Griffin N, Acheson A, Tung P, Sheard C, Glazebrook C, Scholefield J. Quality of life in patients with chronic anal fissure. Colorectal Dis 2004;6:39-44.

38. Keck JO, Staniunas RJ, Coller JA, Barrett RC, Oster ME. Computergenerated profiles of the anal canal in patients with anal fissure. Dis Colon Rectum 1995;38:72-79.

39. Lund JN. Nitric oxide deficiency in the internal anal sphincter of patients with chronic anal fissure. Int $J$ Colorectal Dis 2006;21:673-675.

40. Schouten WR, Briel JW, Auwerda JJ. Relationship between anal pressure and anodermal blood flow. The vascular pathogenesis of anal fissures. Dis Colon Rectum 1994;37:664-669.

41. Klosterhalfen B, Vogel P, Rixen H, Mittermayer C. Topography of the inferior rectal artery: a possible cause of chronic, primary anal fissure. Dis Colon Rectum 1989;32:43-52.

42. Lund JN, Binch C, McGrath J, Sparrow RA, Scholefield JH. Topographical distribution of blood supply to the anal canal. $\mathrm{Br} \mathrm{J}$ Surg 1999;86:496-498.

43. Corby H, Donnelly VS, O’Herlihy C, O'Connell PR. Anal canal pressures are low in women with postpartum anal fissure. Br J Surg 1997;84:86-88.

44. Nelson R. A systematic review of medical therapy for anal fissure. Dis Colon Rectum 2004;47:422-431.

45. Kocher HM, Steward M, Leather AJ, Cullen PT. Randomized clinical trial assessing the side-effects of glyceryl trinitrate and diltiazem hydrochloride in the treatment of chronic anal fissure. $\mathrm{Br}$ J Surg 2002;89:413-417.

46. Antropoli C, Perrotti P, Rubino M, et al. Nifedipine for local use in conservative treatment of anal fissures: preliminary results of a multicenter study. Dis Colon Rectum 1999;42:1011-1015.

47. Brisinda G, Cadeddu F, Brandara F, et al. Botulinum toxin for recurrent anal fissure following lateral internal sphincterotomy. $\mathrm{Br}$ J Surg 2008;95:774-778.

48. Brisinda G, Cadeddu F, Brandara F, Marniga G, Maria G. Randomized clinical trial comparing botulinum toxin injections with 0.2 per cent nitroglycerin ointment for chronic anal fissure. $\mathrm{Br}$ J Surg 2007;94:162-167.

49. Berkel AEM, Rosman C, Koop R, van Duijvendijk P, van der Palen J, Klaase JM. Isosorbide dinitrate ointment vs botulinum toxin $A$ as the primary treatment for chronic anal fissure: a randomized multicentre study. Colorectal Dis 2014;16:O360-O366.

50. Chen HL, Woo XB, Wang HS, et al. Botulinum toxin injection versus lateral internal sphincterotomy for chronic anal fissure: a meta-analysis of randomized control trials. Tech Coloproctol 2014; 18:693-698.

51. Nelson R. Non surgical therapy for anal fissure. Cochrane Database Syst Rev 2006;(4):CD003431.

52. Nelson R, Chattopadhyay A, Brooks W, Platt I, Paavana T, Earl S. Operative procedures for fissure in ano. Cochrane Database Syst Rev 2011;(11):CD002199.

53. Littlejohn DR, Newstead GL. Tailored lateral sphincterotomy for anal fissure. Dis Colon Rectum 1997;40:1439-1442.

54. García-Granero E, Sanahuja A, García-Botello SA, et al. The ideal lateral internal sphincterotomy: clinical and endosonographic evaluation following open and closed internal anal sphincterotomy. Colorectal Dis 2009;11:502-507.

55. Giordano P, Gravante G, Grondona P, Ruggiero B, Porrett T, Lunniss PJ. Simple cutaneous advancement flap anoplasty for 
resistant chronic anal fissure: a prospective study. World J Surg 2009;33:1058-1063.

56. Pelta AE, Davis KG, Armstrong DN. Subcutaneous fissurotomy: a novel procedure for chronic fissure-in-ano. a review of 109 cases. Dis Colon Rectum 2007;50:1662-1667.

57. Mousavi SR, Sharifi M, Mehdikhah Z. A comparison between the results of fissurectomy and lateral internal sphincterotomy in the surgical management of chronic anal fissure. J Gastrointest Surg 2009;13:1279-1282.

58. Engel AF, Eijsbouts QA, Balk AG. Fissurectomy and isosorbide dinitrate for chronic fissure in ano not responding to conservative treatment. Br J Surg 2002;89:79-83.

59. Lindsey I, Cunningham C, Jones OM, Francis C, Mortensen NJ. Fissurectomy-botulinum toxin: a novel sphincter-sparing procedure for medically resistant chronic anal fissure. Dis Colon Rectum 2004;47:1947-1952.

60. Vogel JD, Johnson EK, Morris AM, et al. Clinical practice guideline for the management of anorectal abscess, fistula-in-ano, and rectovaginal fistula. Dis Colon Rectum 2016;59:1117-1133.

61. Steele SR, Kumar R, Feingold DL, Rafferty JL, Buie WD; Standards Practice Task Force of the American Society of Colon and Rectal Surgeons. Practice parameters for the management of perianal abscess and fistula-in-ano. Dis Colon Rectum 2011;54:1465-1474.

62. Gunawardhana PA, Deen KI. Comparison of hydrogen peroxide instillation with Goodsall's rule for fistula-in-ano. ANZ J Surg 2001;71:472-474.

63. Cirocco WC, Reilly JC. Challenging the predictive accuracy of Goodsall's rule for anal fistulas. Dis Colon Rectum 1992;35:537-542.

64. Quah HM, Tang CL, Eu KW, Chan SY, Samuel M. Meta-analysis of randomized clinical trials comparing drainage alone vs primary sphincter-cutting procedures for anorectal abscess-fistula. Int $J$ Colorectal Dis 2006;21:602-609.

65. van Koperen PJ, Wind J, Bemelman WA, Bakx R, Reitsma JB, Slors JF. Long-term functional outcome and risk factors for recurrence after surgical treatment for low and high perianal fistulas of cryptoglandular origin. Dis Colon Rectum 2008;51:1475-1481.

66. Visscher AP, Schuur D, Slooff RAE, Meijerink WJHJ, DeenMolenaar CBH, Felt-Bersma RJF. Predictive factors for recurrence of cryptoglandular fistulae characterized by preoperative threedimensional endoanal ultrasound. Colorectal Dis 2016;18:503-509.

67. Swinscoe MT, Ventakasubramaniam AK, Jayne DG. Fibrin glue for fistula-in-ano: the evidence reviewed. Tech Coloproctol 2005;9:89-94.
68. Sentovich SM. Fibrin glue for anal fistulas: long-term results. Dis Colon Rectum 2003;46:498-502.

69. Cirocchi R, Farinella E, La Mura F, et al. Fibrin glue in the treatment of anal fistula: a systematic review. Ann Surg Innov Res 2009;3:12.

70. Leng Q, Jin HY. Anal fistula plug vs mucosa advancement flap in complex fistula-in-ano: A meta-analysis. World J Gastrointest Surg 2012;4:256-261.

71. Ellis CN, Rostas JW, Greiner FG. Long-term outcomes with the use of bioprosthetic plugs for the management of complex anal fistulas. Dis Colon Rectum 2010;53:798-802.

72. van Koperen PJ, Bemelman WA, Gerhards MF, et al. The anal fistula plug treatment compared with the mucosal advancement flap for cryptoglandular high transsphincteric perianal fistula: a double-blinded multicenter randomized trial. Dis Colon Rectum 2011;54:387-393.

73. Ritchie RD, Sackier JM, Hodde JP. Incontinence rates after cutting seton treatment for anal fistula. Colorectal Dis 2009;11:564-571.

74. Williams JG, MacLeod CA, Rothenberger DA, Goldberg SM. Seton treatment of high anal fistulae. Br J Surg 1991;78:1159-1161.

75. Subhas G, Gupta A, Balaraman S, Mittal VK, Pearlman R. Noncutting setons for progressive migration of complex fistula tracts: a new spin on an old technique. Int J Colorectal Dis 2011;26:793-798.

76. Liu WY, Aboulian A, Kaji AH, Kumar RR. Long-term results of ligation of intersphincteric fistula tract (LIFT) for fistula-in-ano. Dis Colon Rectum 2013;56:343-347.

77. Gendia AMEMA, Abd-erRazik MA, Hanna HH. Ligation of the intersphincteric fistula tract procedure and its modifications. J Coloproctol 2018;38:324-336.

78. Mushaya C, Bartlett L, Schulze B, Ho YH. Ligation of intersphincteric fistula tract compared with advancement flap for complex anorectal fistulas requiring initial seton drainage. Am J Surg 2012;204:283-289.

79. Murugesan J, Mor I, Fulham S, Hitos K. Systematic review of efficacy of LIFT procedure in cryptoglandular fistula-in-ano. J Coloproctol 2014;34:109-119.

80. Wilhelm A, Fiebig A, Krawczak M. Five years of experience with the FiLaC $^{\mathrm{TM}}$ laser for fistula-in-ano management: long-term follow-up from a single institution. Tech Coloproctol 2017;21:269-276.

81. Lauretta A, Falco N, Stocco E, Bellomo R, Infantino A. Anal fistula laser closure: the length of fistula is the Achilles' heel. Tech Coloproctol 2018;22:933-939. 